Note

\title{
Microbioligical Hazard Contamination in Fermented Vegetables Sold in Local Markets in Cambodia
}

\author{
RITHY CHRUN ${ }^{1}$, YUKIE HOSOTANI ${ }^{2}$, SUSUMU KAWASAKI ${ }^{2}$, AND YASUHIRO INATSU ${ }^{2 *}$ \\ ${ }^{1}$ Faculty of Agro-Industry, Royal University of Agriculture, P.O.Box 2696 Dangkor District, \\ Phnom Penh, Cambodia \\ ${ }^{2}$ Food Research Institute, National Agriculture and Food Research Organization, \\ 2-1-12 Kannondai, Tsukuba, Ibaraki 305-8645, Japan
}

Received 15 February, 2016/Accepted 3 April, 2017

\begin{abstract}
Fermented vegetables are common part of Cambodian diet. The food safety status for these foods has not been investigated. This study was conducted to evaluate the microbiological hazards that contaminated fermented vegetables. A total of 68 samples of fermented vegetables were purchased randomly from five wet markets in Phnom Penh. The conventional culture methods for microbiological analysis were used. Coliform bacteria (Escherichia coli, Cronobactersakazakii, and Enterobacter spp.), opportunistic non-Entrobacteriaceae, Enterococcus spp., Staphylococcus spp., and Listeria spp. were found in these fermented foods. The highest contamination rate of Enterococcus spp. was $34 \%$ of total fermented vegetable samples, followed by Bacillus spp. coliform bacteria and $E$. coli $(31 \%, 24 \%$ and $10 \%$, respectively). The potential foodborne pathogen, C. sakazakii, was identified in one sample. Fermented mixed vegetables showed higher contamination rate of coliform bacteria $(50 \%)$ than fermented single-type vegetables $(13 \%)$. The results showed that fermented vegetables sold in wet market are poor in hygiene. The stage in the processing chain where contamination occurred should be identified and basic sanitary practice should be enforced to improve the food safety of fermented vegetables in Cambodia.
\end{abstract}

Key words : Fermented vegetables / Bacterial contamination / Food safety.

Vegetable play an important role in daily dish for the nutrient perspectives. However, the availability of certain fresh vegetables is not stable through the year. Fermentation is one of the oldest methods of food preservation with improving the nutritional value, organoleptic properties and digestibility of food raw material and can remove anti-nutritional factors to make the food safe to eat (Smid and Hugenholtz, 2010; Jägerstad et al., 2005). Therefore, fermented vegetables have an important role in providing foods for the world's population (Battcock and Azam-Ali, 1998).

With the popularity of traditional fermentation, many kinds of fermented Cambodian vegetables have emerged, depending on varieties of domestic raw vegetables, such as cucumbers, mustard greens, carrots, bean sprouts, cabbages, African cabbages, daikon radish, shallots,

*Corresponding author. Tel / FAX: +81-29-838-8067, E-mail : inatu (a) affrc.go.jp papaya etc. Fermentation of vegetables produced in Cambodia generally occurs "spontaneously" by the natural lactic bacterial in surface microflora. These foods are usually prepared by soaking in brine, 5-6\% salt along with single-type vegetable or mixed with other vegetables or ingredients such as ginger, chili, and garlic. It takes only 2-3 days at room temperature $\left(25-35^{\circ} \mathrm{C}\right)$ for fermentation. The obtained goods are sold as soon as possible at wet markets. Some kinds of fermented vegetables, such as fermented salty daikon radishes with high salt concentration (20-25\%), have been dried for few days before storage for long time. The Cambodian fermented vegetables range in $\mathrm{pH}$ from 3.6-6.5, depending on the raw materials and the recipe of fermentation.

The consumption of such lactic acid fermented vegetables helps to enhance human nutrition, to promote the growth of healthy intestinal flora as well as the positive health image of probiotics (Yamano et al., 2006). However, improper handling and contamination of raw 
materials with pathogenic bacteria during marketing could pose a potential risk for the consumers (Inatsu et al., 2004). Foodborne outbreaks are commonly reported in Cambodia, but the scientific reports on food safety status for these foods has not been well documented. Therefore, this study aimed to evaluate microbiological hazards by contaminated fermented vegetables, which were produced and sold in five different open markets in Phnom Penh, Cambodia.

Fermented vegetables were randomly purchased from different wet markets within the city of Phnom Penh, Cambodia. Sixty eight samples were collected in March and July, 2014. The samples were composed of two categories, in which 48 samples were fermented singletype vegetable and the other 20 were fermented mixed vegetables. The purchased samples were put in sterile zippered plastic bags and kept less than 5 days in $5^{\circ} \mathrm{C}$ until the experiments.

Referring the methods used for the surveillances of Thai raw foods (Ananchaipattana et al. 2012), E. coli, Salmonella spp., C. sakazakii, Enterococcus spp., Staphylococcus spp. Bacillus spp. and Listeria spp. were isolated from each of collected samples by conventional culture methods. Chromocult Coliform agar, MLCB agar, Chromocult Enterobacter Sakazaki agar, EF agar, Mannitol Salt agar, NGKG agar and Oxford Agar were used for isolating each of bacteria listed above. These selective media had been purchased from Nissui Co., Ltd., Tokyo, Japan and Merck, Darmstadt, Germany.

Typical colonies developed on the suitable agar plates for the objected bacteria were purified twice on nutrient agar plates and subjected to brief identification by microscopic observation after Gram-staining and oxidase / catalase activities testing. Biochemical analysis including the use of API test kits (BioMérieux, Marcy l'Etoile, France), the immunological test including the use of $\mathrm{NH}$ Immunochromato Listeria (Cosmo Bio Co., Ltd., CA, USA), PS latex (Eiken Chemical C. Ltd. Tokyo, Japan) and polymerase chain reaction (PCR)-based methods including the use of Bacillus cereus (CRS gene) PCR Detection Kit (Takara bio Co. Ltd., Kyoto, Japan) were used for further identification of the bacteria. API $20 \mathrm{E}$, API Staph, API Strep, API Listeria and API 50 CHB test kits were used for identification of coliform bacteria, Staphylococcus spp., Enterococcus spp., Listeria spp. and Bacillus spp., respectively. U.S. food and Drug Administration's Bacteriological Analytical Manual (BAM) was used for references of the obtained results by these test kits.

The contamination rate of each of bacteria in samples was defined as the number of positive samples in the (category of) entire samples. The significance of the differences of contamination rate of bacteria between the one of fermented single-type vegetables and the one of

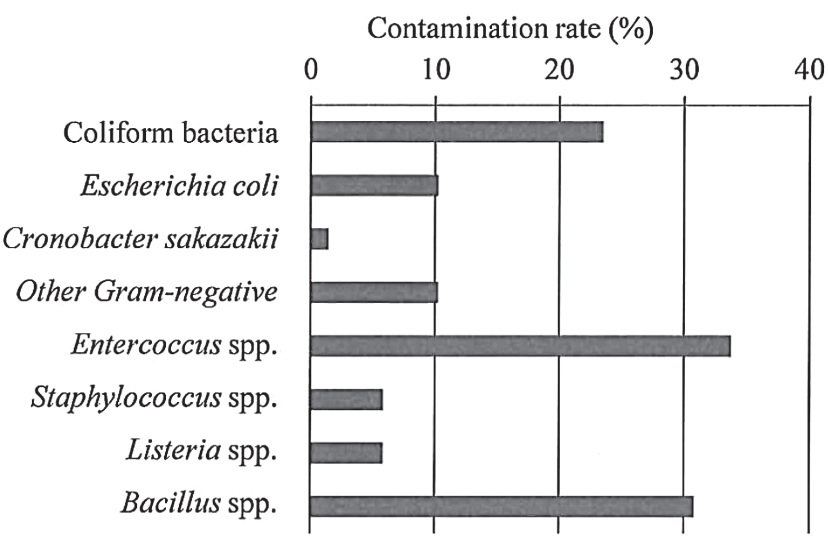

FIG. 1. Contamination rate of spoilage or pathogenic bacteria in collected 68 fermented vegetable samples

mixed vegetables were expressed as the P-values of odds rates calculated by SPSS version 16.0 (IBM Co. Ltd. New York, USA).

Collected 68 fermented vegetable samples could be divided into two categories. The first one consisted of 48 fermented single-type vegetables (mustard greens, cucumbers, shallots, salty daikon radish, salty sweet daikon radish and green papaya). The another consisted of 20 fermented mixed vegetables (cucumber-bean sprout, African cabbage-bean sprout, cucumber-carrotpapaya, bean sprout-chili and bean sprout-cucumberchili-lotus root). All of these samples were qualitative analyzed for hazardous bacteria and some specific spoilage bacteria. The average salt concentration of the each category of samples was $5.6 \mathrm{w} / \mathrm{w} \%$ (for fermented single-type vegetables) and $3.0 \mathrm{w} / \mathrm{w} \%$ (for fermented mixed vegetables), respectively. The average $\mathrm{pHs}$ of the each category of samples were 4.28 and 4.44 , respectively. No significant difference of salt concentration or $\mathrm{pH}$ of collected samples was observed ( $P>0.05)$.

The contamination rate of isolated bacteria in all fermented vegetable samples is shown in Fig.1. The major contamination rate of Enterococcus spp. was $34 \%$ of total fermented vegetable samples, followed by Bacillus spp., coliform bacteria and E. coli (31\%, 24\% and $10 \%$, respectively). The minor contamination rate which was $10 \%$ or below of total fermented vegetables were opportunistic Non-Enterobacteriacae (10\%), Staphylococcus spp. (6\%: no coagulase positive S. aureus was found.), Listeria spp. (6\%). and C. sakazakii (1\%). None of isolated strains were confirmed as Salmonella spp. However, one sample from salty sweet daikon was contaminated with $C$. sakazakii, which is a potential pathogen. Neither cereulide synthesis (CRS) gene harboring $B$. cereus nor enterotoxin producing $B$. cereus was isolated.

All species of Gram-negative and -positive bacteria 
isolated from collected samples were listed in Table 1. Isolated coliform bacteria were identified as Citrobacter freundii, Enterobacter cloacae and Klebsiella pneumonia. Other gram-negative bacteria (opportunistic non-Enterobacteriaceae) were identified as Aeromonas salmonicida., Rhizobium radiobacter and Shwanella putrefaciens group. Gram-positive coccus such as Enterococcus faecalis, E. faecium, E. durans and Aerococcus urina were isolated. Most of opportunistic non-Enterobacteriaceae was isolated from fermented daikon radishes and shallots. $E$. coli and Staphylococcus spp. (S. lentus and S. xylosus) were frequently isolated from fermented mustard greens. E. coli contaminated also some fermented vegetables mixed with bean sprouts such as fermentation of African cabbage-bean sprout and bean sprout-chili. No Listeria

TABLE 1. Isolated bacterial species from total fermented vegetable samples

\begin{tabular}{ll}
\hline Gram negative bacteria & Gram positive bacteria \\
\hline Citrobacter freundii & Enterococcus faecium \\
Cronobacter sakazakii & Enterococcus durans \\
Ewingella americana & Enterococcus faecalis \\
Enterobacter cloacae & Aerococcus urinae \\
Escherichia. coli & Staphylococcus lentus \\
Klebsiella pneumoniae & Staphylococcus xylosus \\
Moellarella wisconsensis & Listeria grayi \\
Rahnella aquatilis & Bacillus cereus \\
Serratia plymuthica & \\
Aeromonas salmonicida & \\
Rhizobium radiobacter & \\
Shewanella putrefaciens group & \\
\hline
\end{tabular}

monocytogenes was isolated from 68 collected samples, however, Listreia grayi (non-pathogenic bacteria) was isolated from fermented shallot, cucumber, papaya and African cabbage samples.

In comparison between two categories of fermentation recipe, fermented mixed vegetables showed higher contamination rate of coliform bacteria (50\%), Enterococcus spp. (50\%) and E. coli (20\%) than those in fermented single-type vegetables (13\%, 27\% and 6\%, respectively) (Table 2 ).

In this study, we evaluated the possibility of the contamination of several potent food poisoning bacteria and spoilage bacteria in fermented vegetables sold in local markets in Cambodia (Fig.1). A high contamination rate of $E$. coli or Enterococcus spp. in fermented foods can indicate direct or indirect contamination with feces; it may also indicate the potent contamination risk of pathogenic bacteria such as E. coli O157:H7 (Keeratipibul et al., 2010). The isolation of E. coli, Citrobacter spp. and Enterobacter spp. from foods is also generally regarded as the possibility of fecal contamination that may cause food poisoning sometime (Leus et al., 2002). In Japan, Ministry of Health, Labor and Welfare reported that $E$. coli was isolated from 262 (12.4\%) of 2118 commercially purchased fermented vegetables during 2005 to 2015; no Salmonella spp. nor enterohemorrhagic E. coli was isolated from these samples. It may require careful consideration to interpret the results of contamination rates of the indicating bacteria.

The minimum $\mathrm{pH}$ for growth of most Enterobacteriaceae is 3.8 (Baylis et al. 2012). However, most of obtained $\mathrm{pH}$ values collected fermented vegetable samples were higher than this value, permit causing contaminated coliforms and $E$. coli to grow or survive in these products. Entrobacter aerogenes and E. cloacae are the most

TABLE 2. Comparison of contamination rate of bacterial strains between fermented single-type and fermented mixed vegetables

\begin{tabular}{|c|c|c|c|c|c|}
\hline \multirow{2}{*}{ Bacterial strains } & \multicolumn{2}{|c|}{$\begin{array}{c}\text { Fermented single-type } \\
\text { vegetables }\end{array}$} & \multicolumn{2}{|c|}{$\begin{array}{l}\text { Fermented mixed } \\
\text { vegetables }\end{array}$} & \multirow{2}{*}{$\begin{array}{l}\text { P-value of } \\
\text { odds ratio }\end{array}$} \\
\hline & Positive / Total & $(\%)$ & Positive / Total & $(\%)$ & \\
\hline Coliform bacteria & $6 / 48$ & 13 & $10 / 20$ & $50^{*}$ & $* 0.05$ \\
\hline Escherichia coli & $3 / 48$ & 6 & $4 / 20$ & 20 & 0.11 \\
\hline Cronobacter sakazakii & $1 / 48$ & 2 & $0 / 20$ & 0 & 0.88 \\
\hline Opportunistic non-Enterobacteriaceae & $6 / 48$ & 13 & $1 / 20$ & 5 & 0.40 \\
\hline Enterococcus spp. & $13 / 48$ & 27 & $10 / 20$ & 50 & 0.10 \\
\hline Staphylococcus spp. & $4 / 48$ & 8 & $0 / 20$ & 0 & 0.35 \\
\hline Listeria spp. & $3 / 48$ & 6 & $1 / 20$ & 5 & 0.84 \\
\hline Bacillus spp. & $17 / 48$ & 35 & $4 / 20$ & 20 & 0.22 \\
\hline
\end{tabular}

The superscript * represents a statistically significant difference in the detection rate $(P<0.05)$ between fermented single vegetable and fermented mixed vegetables. 
frequently encountered human pathogens among the genus Enterobacter (Sanders et al., 1997).

$E$. faecium and $E$. faecalis have been used as an indicator of fecal contamination and an index of processing sanitation (Obaidat and Funs, 2005). A previous study showed that Enterococcus spp. was detected from $73 \%$ of Thai fermented meats and fishes (Ananchaipattana et al., 2012), while in this study contamination rate of Enterococcus spp. in total fermented vegetables was $34 \%$. Although some reports showed that some members of Enterococcus genus have been used as probiotics in food for human health promoting properties (Sivieri et al., 2008), their role in these products has not been fully elucidated. In contrast, it is recognized that $E$. faecium and $E$. faecalis exhibit widespread multiantibiotic resistance (Ananchaipattana et al., 2012) and occurrence of virulence factors (Valenzuelaet al., 2008).

$B$. cereus is a spore forming bacterium, which is commonly found in the environment (e.g. soil) as well as a variety of foods. In general, most of $B$. cereus is harmless. However, some of $B$. cereus can cause two types of foodborne illness, emetic (vomiting) and diarrhoeal syndromes (Schoeni and Wong, 2005; Senesi and Ghelardi, 2010). Previous study reported that $B$. cereus was the most prevalent in fermented meat and fish samples in Thailand (Ananchaipattana et al., 2012). In this case, fermented vegetables were contaminated also at high level rate of $B$. cereus (31\%). The main causes of contamination in vendor foods were the use of improper methods in the preparation, inappropriate holding temperature and poor personal knowledge for hygiene of food handlers (Barro et al., 2006). The presence of Staphylococcus spp. (10\%) and Listeria spp. (10\%) may also point unhygienic food handling procedures, inadequate sanitary processing places, and keeping temperature abuse over a period of time to allow for bacterial growth.

All of the vegetables used for fermentation excepting for bean sprouts were cultivated on / in soil. Even bacterial counts of bean sprouts tend to be higher than ones of the other kinds of vegetables; we could find out only a small difference of bacterial contamination rates that related to the addition of bean sprouts. The obtained results suggest that fermented mixed vegetables containing bean sprouts have significant $(P<0.05)$ higher risk of coliforms contamination than that of fermented single-type vegetables (Table 2). Although the contamination rates of E. coli (20\%) and Enterococcus spp. (50\%) in fermented mixed vegetables were also higher than in fermented single-type vegetables, the difference was not statistically significant $(P>0.05)$. That may due to the small number of collected samples. The result of coliforms may reflect the chance of cross contamination during mixing several kinds of vegetables under unhy- gienic food handling because the more varieties of vegetables are used; the more food handlers are required. The food selling style of both kinds of fermented vegetables were exposed to the flies and dust that can be effective vectors of foodborne illness and should be considered as a risk to food safety (Hinrichs et al., 2014).

This study may provide the first scientific information about the hygienic situation about fermented vegetables distributed in Cambodia. Inatsu et al. (2016) have revealed the difficulty in disinfecting vegetable surface attached E. coli $\mathrm{O} 157$ or contaminated E. coli 0157 into lightly fermented vegetables. The stage in the processing chain where contamination occurred should be identified and basic sanitary practice should be enforced to improve the food safety of fermented vegetables for consumers.

\section{ACKNOWLEDGEMENTS}

This research work was supported by Kirin Holdings Co., Ltd. (formerly Kirin Brewery Co., Ltd.), Tokyo, during UNU-Kirin Fellowship Programme hold at Food Research Institute, NARO.

\section{REFERENCES}

Ananchaipattana, Ch., Hosotani, Y., Kawasaki, S., Pongsawat, S., Bari, M. D. L., Isobe, S., and Inatsu, Y. (2012) Bacterial Contamination in Retail Foods Purchased in Thailand. Food Sci. Technol. Res., 18, 705-712.

Barro, N., Bello, A., Aly, S., Ouattara, C., Ilboudo, A., and Traoré, A. (2006) Hygienic status and assessment of dish washing waters, utensils, hands, and pieces of money from street food processing sites in Ouagadougou, Burkina Faso. African J. Biotechnol., 5, 1107-1112.

Battcock, M.; Azam-Ali, S. (1998) Fermented fruits and vegetables-A global perspective, FAO agricultural services bulletin $\mathrm{N}^{\circ} 134$. Food and Agriculture Organization of the United Nations, Rome.

Baylis, C., Uyttendaele M., Joosten, H. and Davies, A. (2012) The Enterobacteriaceae and their Significance to the Food Industry. Report, Commissioned by the ILSI Europe Emerging Microbiological Issues Task Force.

Hinrichs, G., Jacobsen, J., Kelly Herrera, K., Praxayamoungkhoune, J. and Barcay, J. (2014) Small flies as vectors of foodborne illness: Cross-contamination of food with Escherichia coli by indoor breeding fruit flies., Proceeding of the International Association for Food Protection., p.3-6.

Inatsu, Y., Bari, M. D. L., Kawasaki, S., Isshiki, K. (2004) Survival of Escherichia coli 0157:H7, Salmonella enteritidis, Staphylococcus aureus, and Listeria monocytogenes in Kimchi. J Food Prot., 67, 497-500.

Inatsu, Y., Ohata, Y., Ananchaipattana, C., Bari, M. D. L., Hosotani, Y., Kawasaki, S. (2016) Fate of Escherichia coli 0157 cells inoculated into lightly pickled Chinese Cabbage during processing, storage and incubation in artificial gastric juice. Biocontrol Sci., 21, 51-56. 
Jägerstad, M., Piironen, V., Walker, C., Ros, G., Carnovale, E., Holasova, M. and Nau, H. (2005) Increasing natural food folates through bioprocessing and biotechnology. Trends Food Sci. Technol., 16, 298-306.

Keeratipibul, S., Meethong, S., Techaruwich, P. and Thehuttee, N. (2010) Prevalence of Escherichia coli and Enterococci in a Thai frozen cooked chicken plant, and modeling of cleaning and sanitizing procedure. Food Control., 21, 11041112.

Lues, J., Venter, P. Westhuizen, J., and Westhuizen, H. (2003) Enumeration of Potential Microbial Hazards in Milk from a Marginal Urban Settlement in Central South Africa. Food Microbiol., 20, 321-326.

Obaidat, M. M. and Funs, D. Y. C. (2005) Comparative analysis of Clostridium perfringens, Escherichia coli and enterococci indicators of contamination of ground beef. J. Rapid Meth. Aut. Mic., 13, 225-242.

Sanders, W. E. Jr and Sanders C. C. Enterobacter spp. (1997) Pathogens poised to flourish at turn of the century. Clinical Microbiol. Rev., 10, 220.

Schoeni, JL., Wong, ACL. (2005) Bacillus cereus food poisoning and its toxins. J Food Prot., 68, 636-648.
Senesi, S., Ghelardi, E. (2010) Production, secretion and biological activity of Bacillus cereus enterotoxins. Toxins, $\mathbf{2}$, 1690-1703.

Sivieri, K., Spinardi-Barbisan, ALT., Barbisan, LF., Bedani, R., Pauly, N D., Carlos, IZ., Bezatti, F., Vendramini, R. C., Rossi, E. A. (2008) Probiotic Enterococcus faecium CRL 183 inhibit chemically induced colon cancer in male Wistar rats. Eur Food Res Technol., 228, 231-237.

Smid, E. J. and Hugenholtz, J. (2010) Functional genomics for food fermentation processes. Ann. Rev. Food Sci. Technol., 1, 497-519.

U. S. Food and Drug Administration (1998) Bacteriological Analytical Manual (BAM), US-FDA, USA.

Valenzuela, AS., Omar, NB., Abriouel, H., Lopez, RL., Ortega, E., Canamero, MM., Galvez, A. (2008) Risk factors in Enterococci isolated from foods in Morocco: determination of antimicrobial resistance and incidence of virulence traits. Food Chem. Toxicol., 46, 2648-2652.

Yamano, T., lino, H., Takada, M., Blum, S., Rochat, F. and Fukushima, Y. (2006) Improvement of the human intestinal flora by ingestion of the probiotic strain Lactobacillus johnsonii La1. British J. Nutrit., 95, 303-312. 